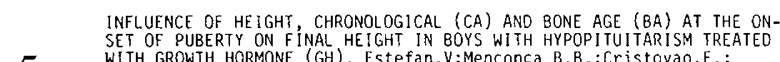
5 WIT GROWTH HORMONE (GH). Estefan, V; Mencon

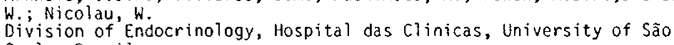
Paulo, Brasil.

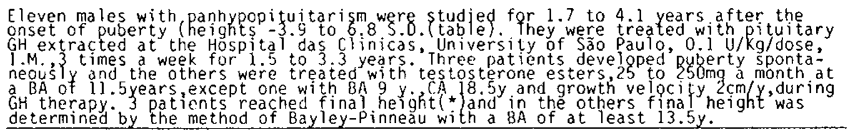

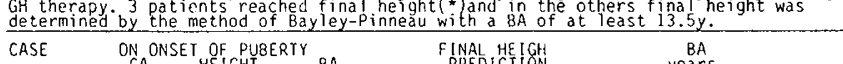

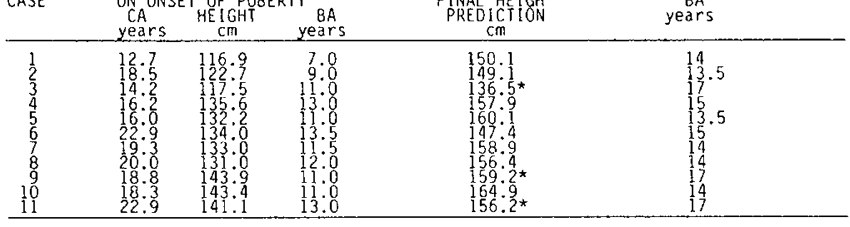

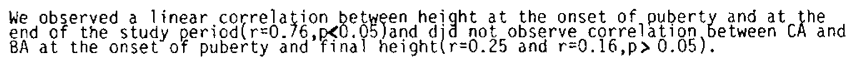

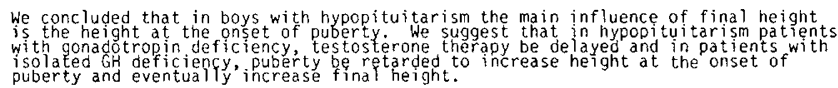

\section{STATURAL GROWTH OF CHILEAN SCHOOL CHILDREN}

S. Muzzo, R. Burrows, L. Leiva. Endocrinology Unit. Institute of

Nutrition and food Technology, University of Chile. Santiago. Chile.

Enviromental and genetic factors are involves in the growth of the human being. It is importante to compare of a population with tables of countries with optimal enviromental factors and with a maximal expression of genetic potential of growth. It seems specially important if from these comparisons programs arise that improve enviromental factors (nutrition, physical activities, education). Genetic factors could differ from one country to another, specially as consequence of ethnic differences. We are interested in knowing growth of school chilean children, and their differences according to sex and socioeconomic level (SEL) in order to build up national tales. A sample of 6140 school age children of Great Santiago Area of Chile was obtained. It was representative of 6 to 16 years old males and 6 to 14 years oid females. The school age children of Great Santiago Area represent around $45 \%$ of the total school children of Chile. Stature was always measured by the same 2 investigators. SEL was evaluated according to a modified Graffar scale obtained through a questionative to the parents. Significants differences in percentiles and averages of stature of our children, compared with NCHS (WHO) tables, were found, These differences were due to a fall in groups channels in our children and is maintained through out different ages. A difference in stature according to SEL was found, being lower for SEL. However, these differences are greater in females than in males; this is similar to previous research in our group that found stature sexual dimorphism due to an earlier pubertal initiation in females of lower SEL compared with females of nigher levels.

GROWTI AND THYROID FUNCTION IN CHILDREN WITII CHRONIC RENAL FAILURE. Zantleifer D, Ferraris J, Granillo E, Fainsten-Day $\mathrm{P}$, Mileo Vaglio R, Gutman RA,Pasqualini I. Hospital Italiano de Buenos Aires, Argentina.

Growth hormone, IGF-1 and thyroid function were evaluated in 12 patients with chronic renal failure treated by continuous peritone al dialysis or hemodialysis. Age ranged from $33 / 12$ to 18 years (median 11 l/2,9 Tanner I and 3 Tanner II). Mean height standard de viation score was $-2.9^{\ddagger}-1.7$. Nine out of 12 patients had height stan dard deviation scores greater than $2 \mathrm{SD}$ below the mean.Growth hormone (GH) was measured by RIA every $30 \mathrm{~min}$ from 9PM to $5 \mathrm{AM}$. Mean nocturnal GH was $3.6^{ \pm}-9 \mathrm{ng} / \mathrm{ml}$. Gll response to arginine $\left(14.5^{ \pm}-11.3\right.$ $\mathrm{ng} / \mathrm{ml}$ ) was $8 \mathrm{ng} / \mathrm{ml}$ in 8 of 12 patients, and it did not correlate with mean nocturnal LH levels. Gll response to GRF $\left(19.8^{+}-20.3 \mathrm{ng} / \mathrm{ml}\right)$, measured in 5 patients, correlated with mean nocturnal GII levels ( $r$ : $0.88 \mathrm{p} 0.05)$. There was no correlation between IGF-I levels $(0.73$ $0.54 \mathrm{UI} / \mathrm{ml}$ ) and spontancous or post-stimulated $\mathrm{GH}$ levels. In $9 \mathrm{pa-}$ tients thyroid hormone levels were:total T4 5.8-1.4ug/dl, total T3 $101 \pm 34 \mathrm{ng} / \mathrm{dl}$, basal TSH $3.4 \pm 1.4 \mathrm{uU} / \mathrm{ml}, 30-60 \mathrm{~min}$ TSH response to TRH $12.2-5.9$ and $90 \mathrm{~min}$ TSII response to TRII $10.9 \pm 6.0$. Free T4 levels $(0.8 \pm 0.3 \mathrm{ng} / \mathrm{dl})$ were low in 5 of 9 patients. Height did not correlate with any of the hormonal levels. We conclude that, although height was low in our patients, mean nocturnal Gll levels were normal. The blunted GII response to arginine in $1 / 3$ of our patients and the delayed TSH response to TRI suggest hypothalamic-pituitary dysfunction.
THE SURFACE OF EPIPHYSIS PF THE KNEE: AN INDEX OF THE 8 ONSET OF NEONATAL HYPOTHYRQIPISM (NH).L. Gruñeiro, A Chiesa and C Bergadå. División de Endocrinologia.Hospi tal de Niños R. Gutiérrez. Buenos Aires. Argentina.

The assesment of skeletal maturation has been considered an important feature of peripheral thyroid hormone action. The surface of the epiphysis of the knee (SE) was calculated, following the method described by Rochiccioli et al, in 30 infants with NH detected in different screenings programs. The anatomical situation of thyroid gland was demonstrated by 131 I or $99 \mathrm{mTc}$ scintigraphy. 25 had athyreosis (Group I) and 5 ectopics glands (Group II). The SE of the distal femoral epiphysis (FD) in all hypothyroids was 10.27 $+2.08 \mathrm{~mm}^{2}$ and that of proximal epiphys is of tibia (TP) was $4.48+$ $1.7 \mathrm{~mm}^{2}$ (Normal values $=F D=26.2+0.79 \mathrm{~mm}^{2} ; T P 213.5+0.38 \mathrm{~mm}^{2}$ ).. Group $I=F D=8.01+1.6 \mathrm{~mm}^{2}$, present in $15 / 25 ; \mathrm{TP}=2.3+1.08 \mathrm{~mm}^{2}$ present in $I=F D=8.01+1.6 \mathrm{~mm}^{2}$, present in $15 / 25 ; T P=2.3+1.08 \mathrm{~mm}^{2}$ present in
$4 / 25$. Group II $F D=21.3+1.08 \mathrm{~mm}^{2}$, present in $\frac{4}{2}, \mathrm{TP}=15.9+7.1 \mathrm{~mm}^{2}$ 4/25. Group II $F D=21.3+1.08 \mathrm{~mm}^{2}$, present in $4 / 5, T P=15.9 \pm 7.1 \mathrm{~mm}^{2}$
present in $4 / 5$. There was significant difference in the 2 group in FD $(p<0.02)$ and TP $(p<0.05)$. No correlation was observed with growth and height attained at 2 and 4 years of age. T4 and T3 serum levels were higher in infants with ectopic glands than athyreosis $p<0.005$. In conclusion:1) the epiphys is of the knee was present in $63 \%$ of infants with $\mathrm{NH}, 2$ ) The SE of both epiphysis was smaller in hypothyroids than in normals 3 ) FD appears in $60 \%$ of infants with athyreosis and $80 \%$ with ectopic glands: TP only in 16 and $80 \%$ respectively, 4)SE was higher in infants with ectopic glands than in athyreosis. Thus, the calculation of SE of the knee may be considered as a criterion of duration and severity of $\mathrm{NH}$ and may be useered as a criterion of duration and severity of $\mathrm{NH}$ and $\mathrm{may}$
ful to judge the onset and degree of thyroid deficiency.

\section{GLAIJD IN CHILDREN AND ADOLESCENTS. Bisi H,}

Clinica Endocrinologica do Hosp. Serv. Půblico Municipal e Departa mento de Patologia USP. Sao Paulo. Brasil.

Between 1981 and 1989, 2000 patients with thyroid nodules underwent fine-needle aspiration biopsy (FNAB) at the Hospital do Servidor Público Municipat de Sao Paulo; out of them, 53 were children and adolescents. The ages varied from 7 to 20 years old, with a mean age of 15 years old; $50(94,3 \%)$ were female and $3(5,6 \%)$ were male.

The cytologic findings showed 20 follicular patterns, 13 inflammatory patterns (10 Hashimoto's thyroiditis, 2 suppurative thyroiditis and 1 Lymphocitic), 6 hemorrhagic cysts, 3 epidermoid cysts, tis and 1 Lymphocitic), 6 hemorrhagic cysts, 3 epidermoid cysts,
2 papillary patterns and 3 Hürthle patterns. In 6 cases, the cyto2 papillary patterns and 3 Hürthle patte

2 cases of Papillary Carcinoma and 1 Hürthle neoplasm diagnosed in the cytology has histological confirmation. No false positives or negatives were reported.

In conclusion, in despite of limitations of the technique, the FNAB provides the clinician a more direct information about thyroid lesion and it is helpful for the evaluation of thyroid nodules in child and

\section{0}

EVALUATION OF THYROXINE (T 4 ) BINDING PROTEINS AND OF THYROID HORMONE: SERUM FRACTIONS IN CHILDREN AFTER CAR DIAC SURGERY. Belgorosky A, Weller $G$, Vega $L$, Iorcansky $S$, Charler E, Sasbon J,Mendíl aharzu J,Rivarola MA.Lab de Invest., and Unidad de Cuidado Intensivo, Hosp. de Pediatrfa "Garrahan", Buenos Aires, Argentina.

Non-thyroidal illness was evaluated in 9 children, chronological age $3.88+3.16$ y $(\bar{X}+$ SD), before (B), immediately after (I), and 24 and $48 \mathrm{~h} \bar{s}$ after cardiac surgery. Serum levels of T-binding globulin (TBG), and $T_{4}$-binding prealbumin (TBPA), albumin (ALB), Total $T_{4}$ and $T_{3}\left(T_{4}, T_{3}\right.$ ), Albound $T_{4}$ and $T_{3}$ (ALB-b $T_{4}$ and $T_{3}$ ), free $T_{4}$ and $\mathrm{T}_{3}$ (by calculation according to the law of mass action) were determined. ALB-b $T_{4}$ was also measured experimentally in undiluted serum, using labelled $T_{4}$ - Serum TGB and TBPA were significantly lo wer in B, I, 24 and 48 hs (TBPA only) $(261+17.05,272+70.17,259 \pm$ $65.47,374+103$, and $3013+625,2870+493,3373+1443,23 \overline{0} 9+398 \mathrm{nmol} / \mathrm{l}$ respective (y) than in controls (C) $(456+71$ and $5999+2226$, respectively, $\mathrm{p}<0.01$ ). Serum TT was significantly lower in I, 24 and 48 hs than in $C(88.12+20,94.91+29.40,105.5+34.27$ and $149+25 \mathrm{nmol} / \mathrm{l}$ than in $\mathrm{C}(88.12+20,94.91+29.40,105.5+34.27$ and $149+25 \mathrm{nmol} / \mathrm{l}$
respect ively, $\mathrm{p}<\overline{0} .01)$. Serum ALB-b $\mathrm{T}_{4}, \mathrm{e}$ ither calculated or experi mentally measured was not different in patients and $C$. Serum $\mathrm{TT}_{3}$ was significantly lower in $B, I, 24$ and 48 hs. than in $C(2.12+0.11$, $1.50+0.57,0.95+0.42,0.92+0.37$ and $3.04+0.61 \mathrm{nmol} / \mathrm{l}$, respectively, $\mathrm{p}<0 . \overline{0} 1)$ as well as free $\mathrm{T}_{3}$ and ALB-b $\mathrm{T}_{3}$ at 24 and $48 \mathrm{hs}$, compared to $c(3.22+1.07,2.15+0.96,330 \pm 11,240+85$ in patients and $7.37+1.9$, $675+178 \mathrm{pmol} / \mathrm{L}$ in $\mathrm{C}$, respectively, $\mathrm{p}<0.01)$. It is concluded that after cardiac surgery in children, al though serum $\mathrm{TT}_{4}$ and $\mathrm{TT}_{3}$ are low, free $\mathrm{T}_{4}$ and ALB-b $\mathrm{T}_{4}$ are normal. 